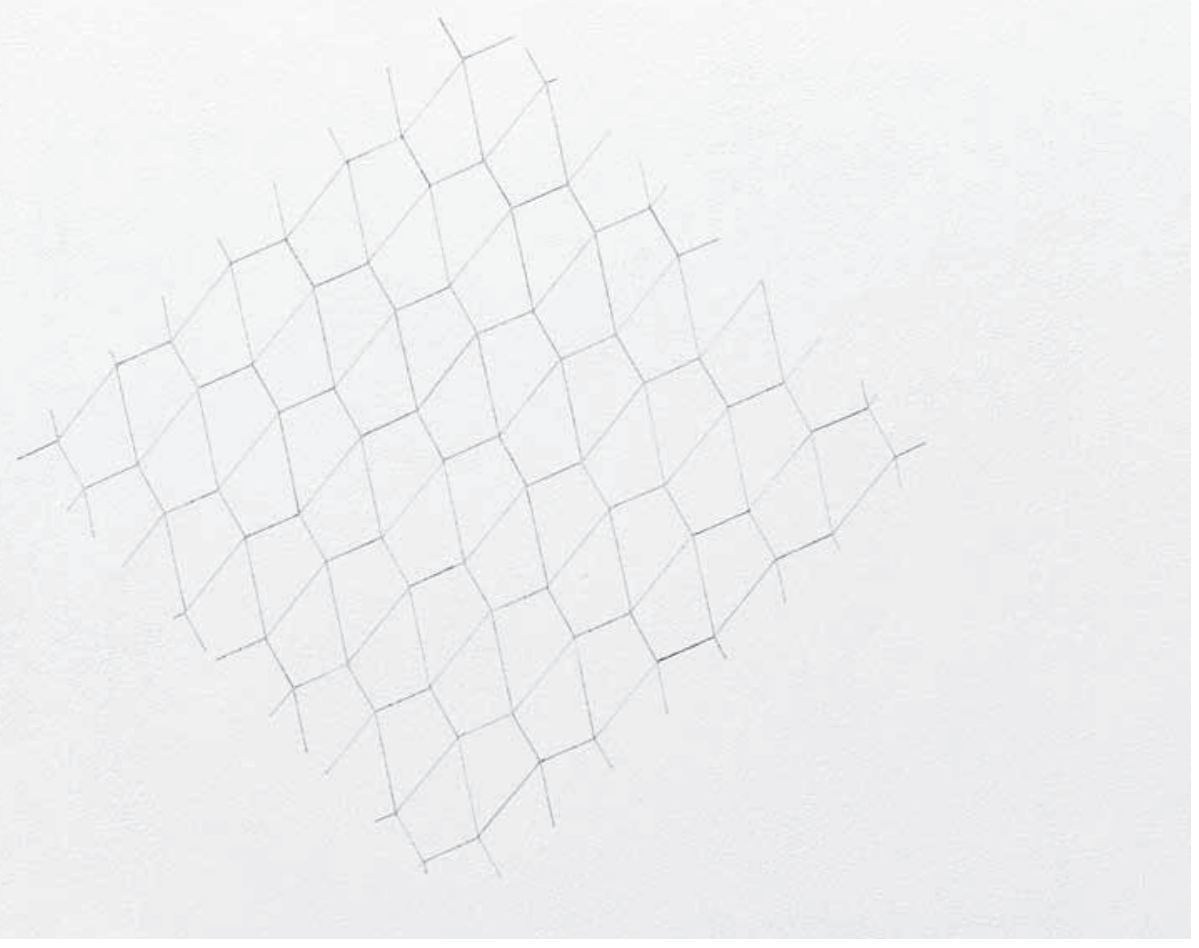




\section{Good Morning, Warsaw}

palavras-chave: exposições de arte contemporânea com tema brasileiro no mundo todo; arte brasileira como produto de exportação e como marca; crítica institucional; relações culturais entre Polônia e Brasil.

keywords: Brazil themed exhibitions of contemporary art worldwide; Brazilian art as export product and branding; institutional critique; cultural relations between Poland and Brazil.
Este texto foi concebido em conjunto com a exposição Amor e ódio a Lygia Clark / Love and Hate to Lygia Clark, na Zachęta Gallery, Varsóvia (13/12/2013 - 23/02/2014), mas permanecia inédito até o momento. Nerefuh e Maier refletem sobre a explosão de exposições de arte contemporânea com tema brasileiro no mundo todo durante as primeiras duas décadas do século XXI.

This short text was originally prepared for the exhibition "Amor e ódio á Lygia Clark / Love and Hate to Lygia Clark", at Zachęta National gallery of Art, Warsaw (13/12/2013 - 23/2/2014), yet remained unpublished to date. Nerefuh and Maier reflect upon the surge of Brazil themed exhibitions of contemporary art worldwide during the first two decades of the 21 st century.
* Universidade de São Paulo (USP).

Daniel Steegmann Mangrané, Axolotlism na NoguerasBlanchard em Madrid, 2015. 
Estamos pensando no Brasil (e na Polônia) enquanto um violonista toca uma música escrita em 1991 pelos Scorpions, The wind of change [Os ventos da mudança], na Praça do Patriarca, uma praça pública em pleno centro de São Paulo. Para mim (Tobi Maier, imigrante alemão no Brasil), é surreal ouvir uma música que, de algum modo, conecta-se à queda do Muro de Berlim e evoca imagens dos cidadãos da RDA vestidos com jaquetas jeans estonadas, ébrios de alegria. As lembranças se confundem.

Ao contrário das regiões mais abastadas da cidade, nas quais a própria noção de espaço público foi completamente sequestrada pelo ideal da comunidade murada, o centro de São Paulo ainda ostenta algumas áreas e praças públicas sobreviventes, como a Praça do Patriarca, onde estamos no momento. Um grupo peruano de sopros toca ao lado de um palhaço que dança e acompanha nas castanholas uma canção de Elvis Presley; um desabrigado louva a Jesus diante de uma igreja; e alguém defende aos brados os direitos dos negros no Brasil. Nos últimos tempos, a prefeitura, adjacente à praça, tem enfrentado protestos quase todos os dias. Dentre as numerosas reivindicações, os vendedores ambulantes de cachorro-quente recentemente manifestaram em prol de seus direitos comerciais em uma van que distribuía hot-dog grátis. A esfera pública é transformada diariamente em palco dramático.

Ressoam com The wind of change os protestos dos professores nas ruas do Rio de Janeiro; os protestos contra o aumento de preço do transporte público em São Paulo; os protestos contra a venda dos campos petrolíferos brasileiros; contra a violência rural, urbana e suburbana; contra os gastos com campeonatos mundiais de futebol e as Olimpíadas e o deslocamento de comunidades indígenas devido a projetos de construção; contra a corrupção e a enorme burocracia que tanto entravou a vida pública; a falência dos projetos de mineração e construção imobiliária do homem outrora detentor da maior fortuna do Brasil, Eike Batista. Os ventos da mudança e o desejo por um novo projeto nacional são palpáveis.

\section{II}

Nos anos 1920, novos imigrantes oriundos da Europa Ocidental e Oriental chegavam ao Brasil, estimulados pela nova riqueza gerada pela comercialização e industrialização do café. Em São Paulo, automóveis e charutos suscitaram novos hábitos modernos em uma sociedade
Leandro Nerefuh

Tobi Maier

Bom dia, Varsóvia
1. Este texto foi concebido em conjunto com a exposição Amor e ódio a Lygia Clark / Love and Hate to Lygia Clark, na Zacheta Gallery, Varsóvia, mas permanecia inédito até o momento. 
ARS fundada no agronegócio. A Semana de Arte Moderna de 1922, orgaano 13 nizada por Emiliano di Cavalcanti e Mário de Andrade, trouxe expo-

n. 25 sições, concertos e poesia ao Teatro Municipal e estabeleceu a cidade como sede do novo movimento modernista nas artes. Em 1926, Gregori Warchavchik, arquiteto imigrante de Odessa, construiu a primeira casa modernista em São Paulo. Em 1928, o Manifesto Antropofágico de Oswald de Andrade convidava a "devorar nosso colonizador de maneira a nos apropriar de suas virtudes e poderes e transformar o tabu em totem”. Embora a própria noção de identidade nacional tenha como base, historicamente, a hibridização - europeus brancos, africanos negros e americanos indígenas, designados como as três matrizes da cultura brasileira - o discurso sociocultural hegemônico desenvolveu-se na direção de um Brasil Euro-Brasileiro (como o denomina a artista Maria Alves), no qual a maior população negra do mundo, atrás apenas da Nigéria, continua a ser excluída, e os direitos dos povos indígenas e outras "minorias" silenciados.

Atualmente, nativos de países vizinhos da América Latina, como a Bolívia e o Peru, bem como espanhóis e outros europeus (que sofrem os efeitos da crise global) e africanos subsaarianos estão desembarcando no país, sobretudo em São Paulo, em busca de seu quinhão na nova opulência do Brasil, de modo que, mais uma vez, a face pública da cidade está se tornando mais multicultural.

\section{III}

Diante desse pano de fundo e concomitantemente a uma economia que parece estar em pleno crescimento, uma série de exposições de arte contemporânea com tema brasileiro vem pululando em diferentes partes do mundo. A história recente das exposições internacionais com tema inspirado no Brasil inclui Brazil: body and soul no Guggenheim de Nova York, que ocorreu em 2001/2002 e apresentou "Obras-primas barrocas dos séculos XVII e XVIII, junto com obras excepcionais da arte moderna e contemporânea" e incluía uma "justaposição de trabalhos importantes de artistas indígenas, afro-brasileiros e europeus estabelecidos no Brasil". Dois anos depois veio Entre Pindorama no Künstlerhaus de Stuttgart. Ao passo que Entre "nos convida a entrar a conhecer e discutir a arte brasileira", Pindorama define "a terra das palmeiras - lar da população nativa do Brasil”. Inspirada nas ideias de uma corrente da arte moderna brasileira - a Antropofagia, uma visão 
de renovação cultural - a exposição "defendia uma forma de contato Leandro Nerefuh positiva e empática com o Outro". Dois anos mais tarde tivemos Tropicália, que foi levada ao Museu de Arte Contemporânea de Chicago, Tobi Maier

Bom dia, Varsóvia ao Museu de Artes do Bronx em Nova York e ao Barbican de Londres (2006), tendo como base um movimento cultural multidisciplinar que surgira durante a era da ditadura militar. De acordo com a assessoria de imprensa, "O movimento da Tropicália foi uma resposta apaixonada e inteligentemente articulada à ditadura militar, a declaração contracultural definitiva - uma verdadeira revolução que redefiniu as artes no Brasil e remodelou a identidade brasileira. Ela representaria uma breve explosão de transformação e agitação cultural, estendendo-se por um período de menos de cinco anos, de 1967 a 1972".

E atualmente podemos visitar diversas outras exposições (coletivas) com tema brasileiro durante a apresentação brasileira na Feira do Livro de Frankfurt; além de: Conversation pieces (Neuer Berliner Kunstverein, Berlim), Imagine Brazil (Museu de Arte Moderna Astrup Fearnley, Oslo), Cruzamentos: contemporary art in Brazil (Wexner Center for the Arts, Columbus, Ohio) e, é claro, Amor e ódio a Lygia Clark / Love and hate to Lygia Clark (Zachęta, Varsóvia).

É notável que todas essas exposições estejam ocorrendo durante este segundo semestre de 2013 e primeiro semestre de 2014. Parece haver um repentino aumento de interesse internacional na produção de arte contemporânea no Brasil, especialmente pelos jovens artistas. Esse fenômeno diz muito sobre o discurso atual que vem sendo promovido no país - uma ênfase na florescente produção artística brasileira que anda de mãos dadas com a especulação de um novo mercado de colecionadores, galerias, museus, artistas, leilões e feiras. Os mecanismos que operam na produção de arte com tema brasileiro (no Brasil como no exterior) parecem criar e promover a ideia de uma arte nacional. Ao mesmo tempo, o capital global que se embrenha no país segue a lógica neoliberal da especulação: explorar as novas fontes de riqueza enquanto elas durarem, passando em seguida a outra coisa (Índia, México, Brasil, China, Rússia). E em certa medida sentimos que essas exposições funcionam como um espelho para a situação conservadora do mundo da arte nas principais capitais do Brasil. Todas essas exposições apresentam poucas artistas mulheres, pouquíssimos negros e quase nenhum indígena, raríssimos ou nenhum artista brasileiro que viva fora do Brasil ou que trabalhe em contextos externos às principais capitais artísticas do país. 
Nessa trajetória de especulação, a estética do modernismo brasileiro emerge como uma moeda internacional que conecta o país a um discurso e uma história da arte globais.

$\mathrm{O}$ atual interesse em apresentar e representar o "Brasil Moderno" internacionalmente vem atraindo jovens artistas brasileiros, bem como dezenas de artistas e curadores internacionais: enquanto alguns negociam seu trabalho com esse legado, outros sentem que devem fazê-lo porque o caminho já está traçado. Nesse sentido, o grande projeto moderno de delinear um novo futuro para o país pode ser rapidamente transformado em uma dupla apreensão neocolonial do país - tanto pela elite nacional quanto pelo capital internacional. Assim, paradoxalmente, os horizontes utópicos de uma civilização alternativa (ou seja, um Brasil Moderno híbrido e complexo) retraem-se enormemente diante desse novo ímpeto de um "Brasil Moderno" para exportação.

\section{IV}

Na Zachęta, o público terá a chance de se envolver com uma cuidadosa seleção de obras de arte, projetos especialmente encomendados e performances ao vivo que buscam refletir de forma crítica sobre esse paradoxo do "Brasil Moderno" contemporâneo, além de apresentar novas narrativas alternativas - de releituras do legado colonial à música funk contemporânea.

A Polônia e o Brasil estão culturalmente conectados através de uma história de imigração polonesa para o Brasil (no século XIX), um intenso intercâmbio de arte conceitual e redes de arte postal durante o socialismo e a ditadura militar (no século XX) e as analogias que existem dentro da tradição construtivista entre artistas de ambos os países. Esperamos que esta exposição possa contribuir para a renovação do diálogo entre os dois países e que o público da Zache ta seja capaz de traçar novos paralelos, levando em conta as deficiências, mas também as novas possibilidades inerentes ao projeto moderno e contemporâneo, tanto na vida sociocultural brasileira quanto na polonesa. 
Leandro Nerefuh (1975) vive em São Paulo e é graduado em História da Arte (Goldsmiths College, 2007) e mestre em Estudos Culturais (London Consortium, 2009). Trabalha com a tradução formal de narrativas históricas, com especial interesse na América Latina. Entre exposições recentes, destacam-se "Radical Software", W139, Amsterdam; "330 Panorama da Arte Brasileira", MAM-SP; "Agitprop Abyssal", Galeria Nacional ZachĐta, Varsóvia; "Contra Escambos", Palácio das Artes, Belo Horizonte; "Mobile Radio", 30a Bienal de São Paulo; "Arquivo Banana", 17o Festival Sesc VideoBrasil; "Memórias Disruptivas", Museu Reina Sofia, Madrid; "Talk Show", Institute of Contemporary Arts, Londres. Exposições futuras incluem 12a Bienal de Havana; e Kunstenfestivaldesarts, Bruxelas. Leandro é também colaborador da Escola Capacete (Rio de Janeiro), e fundador do PPUB, Partido pela Utopia Brasileira, atuante no Brasil, Paraguai e Uruguai. É cofundador do espaço expositivo SOLO SHOWS, em São Paulo.

Tobi Maier vive em São Paulo e é critico de arte, curador, docente e editor. Atuou como curador no Frankfurter Kunstverein (2006-2008) e no MINI / Goethe-Institut Curatorial Residencies Ludlow 38, em Nova lorque (2008-2011). Foi curador associado da 30a Bienal de São Paulo (2011-2012) e coeditou as publicações OEI \#60/61 Extra-disciplinary spaces and de-disciplinizing moments. In and out of the 30th Bienal de São Paulo em 2013 e OEI \#66 poema/processo em 2014, entre outros. É mestre em Estudos Curatoriais pelo Royal College of Art, Londres, Reino Unido e doutorando em Poéticas Visuais (ECA-USP). Contribui desde São Paulo para várias revistas de arte contemporânea incluindo Artforum, Frieze e Aperture. Tobi Maier é co-fundador do espaço expositivo SOLO SHOWS em São Paulo.

\section{Leandro Nerefuh}

Tobi Maier

Bom dia, Varsóvia
Leandro Nerefuh, Caverna de Umbelina, 2015.

Artigo recebido em 18 de dezembro de 2014 e aprovado em 26 de janeiro de 2015. 


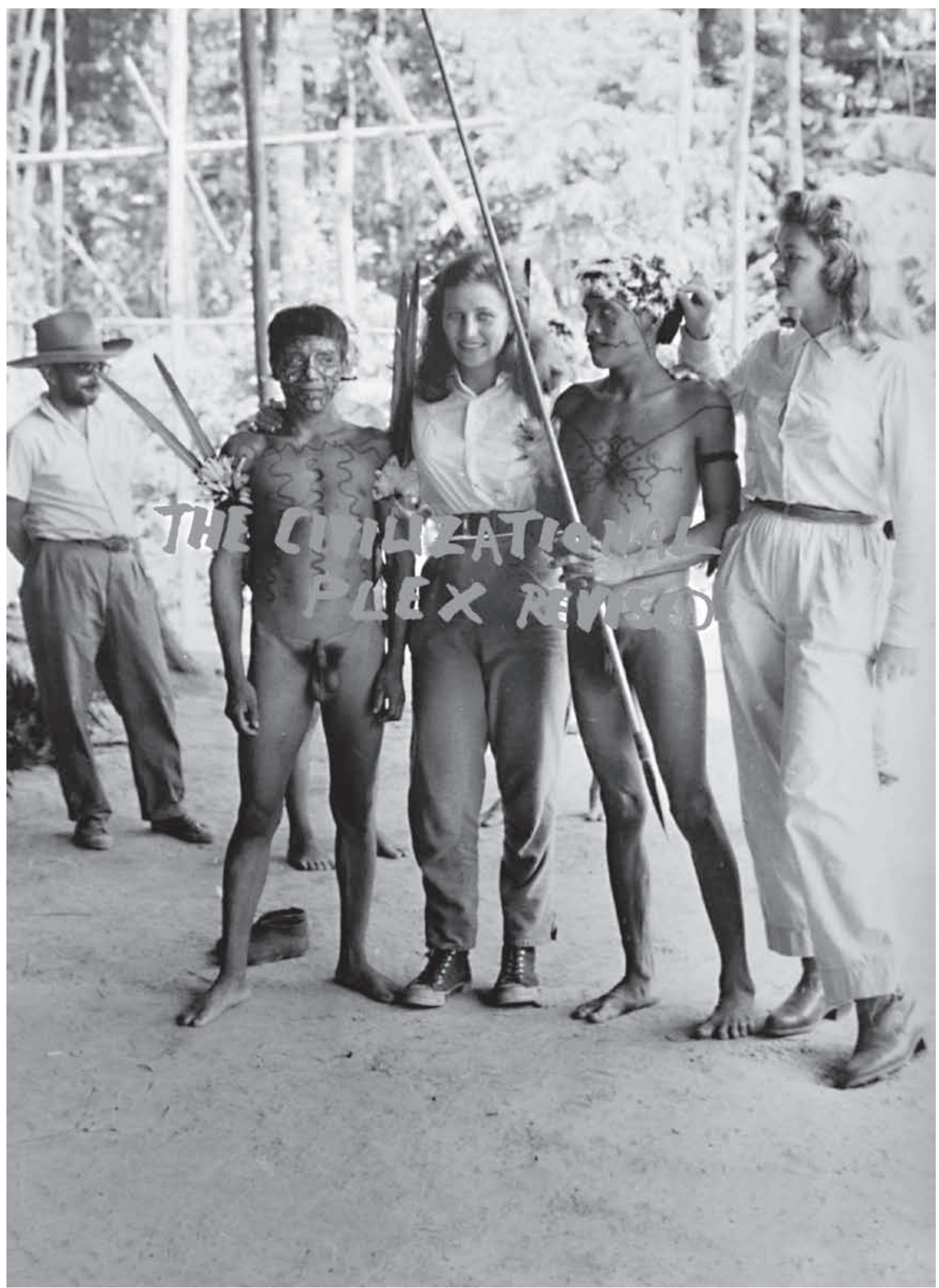

